\title{
Asking for the Moon . . .
}

\section{Tokyo}

Astronomy and space science come out winners in the budget request for science submitted by Japan's Ministry of Education, Science and Culture (MESC) at the end of last month.

The budget request will be whittled down in negotiations with the Ministry of Finance before the end of the year, but is unlikely to suffer major change. The key negotiations over the budget occur internally within MESC before submission to the finance ministry.

As expected, MESC has at last decided to give full backing to a project to build one of the world's largest optical infrared telescopes in Hawaii (see Nature 346, $686 ; 1990)$. The ministry has applied for $¥ 650$ million (\$4.6 million) for equipment for the telescope and $¥ 13$ million for other expenses. Construction is expected to take eight years.

Under the original plan proposed many years ago, the single-mirror telescope was to have had a diameter of 7.5 metres. But a study this fiscal year has shown that present-day technology is capable of making a larger mirror, so the size has been increased to 8 metres. This will make the Japanese telescope one of the largest in the world (a 10-metre optical infrared telescope is now being constructed by California Institute of Technology in the United States).

On the other hand, MESC fears that the Ministry of Finance will balk at last year's estimated cost of $¥ 45,000$ million ( $\$ 320$ million) for the telescope, so the projected cost has been reduced to $¥ 38,000$ million by including only "essential facilities", according to Makoto Kinoshita of MESC's research institutes division. Not so lucky is a competing proposal to build the world's largest observatory for neutrinos and proton decay (see Nature 331, $379 ; 1990)$. The observatory, called Superkamiokande, would be built in a mine in Gifu Prefecture. But, contrary to the expectations of some supporters of the scheme, MESC has decided not to apply for specific funds for the project next year. Rather, it hopes to find some money for excavating a hole for the observatory from general construction funds which will not be allocated until March next year. Until then, the future of the project remains uncertain.

MESC has decided to go ahead with a second mission to the Moon proposed by the Institute of Space and Astronautical Science (ISAS) as a follow-up to this year's successful lunar launch (see Nature

344, 693; 1990). The ministry has applied for $¥ 400$ million ( $\$ 2.9$ million) to start development of the lunar satellite expected to be launched in early 1996; it will drop seismometers onto the lunar surface to monitor "moonquakes". The budget for space also rises because of increased development costs for a new and larger solid-fuel rocket $(\mathrm{M}-\mathrm{V})$ that ISAS is developing for the lunar mission and missions to the planets.

The increased support for astronomy and space science is affecting other parts of MESC's overall budget for science because of strict budget limits laid down by

\section{MESC BUDGET REQUEST}

\begin{tabular}{cc}
$¥ 000$ million & $\begin{array}{c}\text { \% Change } \\
\text { from } 1991\end{array}$ \\
59.0 & +5.7 \\
13.4 & +16.5 \\
44.3 & +13.0 \\
8.8 & -1.8 \\
15.8 & -2.7 \\
21.3 & +18.2 \\
1.7 & +95.3 \\
2.3 & +1.4 \\
3.3 & -35.8 \\
2.4 & +12.3 \\
6.7 & +8.7 \\
\hline
\end{tabular}

the Ministry of Finance. Among the projects to suffer is TRISTAN, the giant electron-positron collider at the High Energy Physics Laboratory (KEK) in Tsukuba. Operating hours for the accelerator, which runs up huge electricity bills when switched on, will be reduced by 100 hours to 2,800 hours in 1991. TRISTAN was recently criticized in the influential economic newspaper, the Nihon Keizai Shimbun, for failing to reach its goal of finding the top quark. And some senior Japanese physicists at TRISTAN have left for other jobs.

Some scientists are pressing MESC to convert the main ring of the collider into the world's largest synchrotron (offering energies of up to $10 \mathrm{GeV}$ ). But Kinoshita says TRISTAN still has many important scientific investigations to carry out and MESC intends to continue supporting the accelerator for at least the next few years.

David Swinbanks

\section{Correction: Animal Welfare Institute}

A SENTENCE in the 30 August article on US animal regulations entitled "One step forward ..." (Nature 346, 782; 1990) incorrectly paraphrased William Cotreau of the Animal Welfare Institute on the frequency of inspections of dog dealers. Federal officials were unable to inspect one-quarter of all dog dealers in 1988, not three-quarters, as the article implied.

\section{Budget brings a little cheer}

\section{Sydney}

EDucation came out a winner in the Australian federal budget announced at the end of August, making it almost certain that significant pay rises are on the way for academics. Scientific research did less well overall, having received a major boost in last year's Science and Technology Statement.

Until now, salaries for academics have been "insulated from wage movements in the rest of community", according to Wayne Burns of the Department of Education. But thanks to the budget increase, salaries will be set by the Australian Industrial Relations Tribunal in line with wages in other sectors. Junior academics and postgraduate teaching assistants are expected to benefit most. Graduates will lose from changes - they will be expected to repay their fees more quickly after they have graduated and obtained jobs. The Commonwealth Scientific and Industrial Research Organization (CSIRO) came out at a net loss. Although given an extra $\mathrm{A} \$ 4.1$ million for new projects in addition to an increase of A $\$ 30.1$ million won under a three-year agreement, CSIRO also lost A $\$ 3.8$ million as part of a plan to promote efficiency in the organization. As a result, "existing activities will be cut in real terms", says Lindsay Bevege of CSIRO.

A key element of the budget is funding to establish 50 Cooperative Research Centres over the next five years. The centres will be located next to universities and will receive matching funds from state governments and industry. The budget allocates $\mathrm{A} \$ 4$ million for 15 centres in 1990-91.

Medical research funding provided few surprises, with the National Health and Medical Research Council receiving A\$99 million for next year. But a new capital works programme costing $\mathrm{A} \$ 45$ million over five years was introduced. Institutes will have to compete for funds and their bids will need to demonstrate "a potential for commercial exploitation of research results", according to Brian Howe, the Minister of Health. Once again, matching funds are expected from state governments and industry.

AIDS funding received a significant boost with an extra A $\$ 78.3$ million for 1990-91, including a 47 per cent increase to A $\$ 47.2$ million for AIDS education, prevention and support services. AIDS research funding rose by 52 per cent to A $\$ 7.6$ million but researchers are unhappy that the government did not provide a A $\$ 500,000$ increase to compensate for inflation which was promised last year.

Tania Ewing 